\title{
Architectural integration of ETICS in building rehabilitation
}

\begin{abstract}
ETICS (external thermal insulation composite system) is one of the most frequently used thermal retrofitting solutions in the construction market. This study examines the architectural integration of this system in the rehabilitation of façades. When thermal retrofitting of the outer envelope is required to comply with thermal code demands ETICSs have to be harmonised with the various elements of the façade. To that effect, several proposals for the architectural integration of the system are made, and relevant parameters of costs, durability, feasibility and architectural integration are analysed for each of the solutions.
\end{abstract}

Keywords: ETICS, rehabilitation, architectural integration, façades, thermal retrofitting. 


\section{INTRODUCTION}

This study's main goal is to integrate ETICS (External Thermal Insulation Composite System) in the rehabilitation the façades of residential buildings constructed since the second half of the $20^{\text {th }}$ century. It is well known that these buildings often do not comply with today's minimum standard requirements of thermal comfort, given the characteristics of their outer envelope, as demonstrated in various studies (Dylewski and Adamczyk 2011). Furthermore, they are responsible for a large segment of the overall energy consumed through warming and cooling. However, the construction sector is becoming increasingly aware of the financial and ecological benefits of thermal retrofitting (Lucas and Ferreira 2010).

The rehabilitation of buildings is a part of sustainable development and also a cultural attitude, since it contributes to the preservation of cities as they develop (Vaz-Sá et al. 2007). This explains the rising importance of the durability and sustainability of buildings in various studies (Mills et al. 2012) (HHA 1999) and of maintenance planning in all stages of the building process, from design to end of service life (Silva and Falorca 2007).

Several solutions have been developed for the external claddings of buildings in recent decades, based on new materials and technologies that need to be analysed under a variety of conditions (Barreira and Freitas 2007), side by side with thermal retrofitting solutions. These solutions have offered improvements in terms of durability, thermal performance and finishing surface (Collina 2007). This is the case of ETICS, an external thermal retrofitting solution that is being increasingly widely used in many countries (Barreira and Freitas 2005). It is suitable for façade rehabilitation, since it enables relevant anomalies to be corrected and provides exterior aesthetic renovation (Pereira et al. 2007).

Notwithstanding the system's well-known advantages, described in various sources 
(Collina 2007) (Malanho and Veiga 2011) (EIMA 2008), one of its drawbacks is that it changes the façade's characteristics, which has to be discussed when architectural integration is an issue. However, given the objectives of thermal retrofitting the outer envelope and complying with the present-day thermal code demands, harmonisation of ETICS with the façades is both feasible and necessary. The solutions for the architectural integration of ETICS presented here are based on existing ones and applied to rehabilitation/thermal retrofitting projects and the various elements that constitute a façade. The solutions and their evaluation are seen as a starting point for decision-making and further advancing the architectural integration of ETICS in building rehabilitation.

\section{METHODOLOGY}

The research reports on the application of ETICS to housing building façades. Most of the buildings used in the analysis were located in Lisbon City, although the conclusions are general to any residential building of traditional construction. The execution process and the main difficulties in rehabilitation situations are analysed, in particular the harmonisation with the various elements that make up a façade, where unwanted changes in its external appearance may result. The various constructive solutions for external walls were illustrated with the aid of the specialised literature and a photo survey of a considerable number of residential buildings. The walls studied were made mostly of ceramic hollow brick masonry, which support various typical solutions for

integrating the system according to the procedures and characteristics of ETICS solutions already installed.

The first step in designing the solutions is to make rough drawings of each one, supported on the existing façade elements. After detailing and illustrating the solutions the results are analysed and evaluated empirically in terms of parameters such as 
architectural integration in the façade, practicability, level of costs and durability. The measures taken to integrate the system in rehabilitation work are described.

The characteristics of the components of ETICS were taken into account when preparing the details, from the substrate to the final finishing coat and the fastening elements/solutions.

\section{THERMAL RETROFITTING WITH ETICS}

Thermal retrofitting solutions for external walls to insulate them have advantages over those applied either to the interior of these walls or inside the air-box of double-panel walls. These systems significantly improve thermal comfort and they are mostly chosen for functional aesthetic reasons (Paiva 2003), besides preventing the risk of internal condensation when compared with other solutions.

One such solution is ETICS, which perform well in masonry walls and offer the same durability as a traditional rendered façade (Künzel and Zirkelbach 2008). These systems are known to be aesthetic solutions, with good thermal resistance, thus contributing to efficient energy consumption. It is therefore important that they are applied with the minimum of execution errors in order to guarantee the system's technical performance and durability, as long as the buildings are maintained correctly (Silva and Falorca 2009).

\subsection{The system}

ETICS was first used in the early 1960s in Europe (Pereira et al. 2007) (Künzel et al. 2006) and North America (Daniotti et al. 2011), with the economic crisis and later on the oil crisis (Barreira and Freitas 2008), when the cost of heating buildings and the scarcity of fuel led to a demand for solutions that would reduce energy consumption by avoiding thermal losses by improving the thermal insulation of the building envelope. 
One of the main concerns has been to provide masonry walls with a good thermal performance, in both existing buildings and new construction. Reportedly, the system has rarely been unsuccessful from this point of view (Silva and Falorca 2009) (Künzel et al. 2006).

ETICS is made of a thermal insulation board, usually expanded moulded polystyrene (EPS) glued to the substrate, a thin coat of synthetic or mixed binder reinforced with a flexible mineral mesh such as fiberglass, a base and primer coat and a finishing layer of a thin coat of synthetic binder (Malanho and Veiga 2011) (Collina and Lignola 2010).

The surface finishing that it provides is similar to that of traditional render, with a sand paint coat, even though texture and other materials' characteristics may vary, and it guarantees a renovated façade in a rehabilitation operation without having to completely remove the original cladding, as long as this duly checked (EAE 2011). The system still allows some diversity in terms of finishing since it supports discontinuous claddings such as ceramic and stone. It is stressed that these claddings are not covered by the ETAG 004 guide (EOTA 2000), as noted by Malanho and Veiga (2011).

When the masonry consists of hollow ceramic bricks the mechanical fastening cannot be properly ensured and the system and cladding must be glued in a suitable manner.

The watertightness of the cladding, together with the stress distribution via the reinforcement, which reduces the risk of cracking, protects the system from rainwater infiltration. For single-panel walls the system has a competitive cost. It can be applied over heterogeneous substrates since it adapts to their minor discontinuities and settlements, and over areas with small/thin relatively stabilised cracking (EOTA 2000).

\subsection{Application of ETICS in rehabilitation}

ETICS must follow some principles when used in rehabilitation works. First, the outer 
envelope to be cladded and the detailing of the system design must be studied so that the solutions chosen can be adapted to the façade's characteristics, using adequate materials and employing a careful execution (EAE 2011), with the correct preparation of the substrate.

According to the literature (EAE 2011) (Freitas 2002), catalogues and advice from ETICS installers, some of the principles to be followed relate to protecting the system from rainwater, protecting façades accessible to the public from impacts, the minimum thickness of the insulation, the exposure of the façades to certain degradation agents and the type of finishing envisaged. Therefore, when the system is detailed and installed it must be ensured that water cannot penetrate through the joints with other construction elements by fitting drip moulds at the lower limits of the system (Figure 1) and in protruding elements and preventing water from dripping directly onto the façade.

\section{[INSERT FIGURE 1]}

Furthermore, the perforated profiles at the edges of the cladding must be covered with a sufficiently thick finishing coat (Freitas 2002). The system must be designed to slope towards the exterior so as to drain water, and there must be a $3-4 \mathrm{~cm}$ projection horizontal to the façade's plane, with drip moulds at the end of the protruding elements. There must be a groove or a small duct in the edges of parapets or window sills to stop the water from draining onto the wall.

In rehabilitation it is important to evaluate and, if necessary, alter the design of the edge finishings and upper protection of the façade panels. The design/shape of any eaves or cornices may have to be changed.

If a wall is likely to be affected by factors such as wind and rain exposure and risk of impact then special care is required when choosing the system. Wind exposure matters

to systems that are directly adhered to the substrate and it is recommended that an 
auxiliary mechanical fastening is used, as long as the substrate allows it (EAE 2011) (Freitas 2002).

Similarly the colour envisaged for the wall depends on its exposure to sunlight, since darker shades tend to absorb more heat and so lighter colours tend to be chosen. Using dark colours in ETICS can increase the deterioration rate, given the higher thermal gradient effect (see more in Daniotti and Paolini, 2008 and Norvaisiene, et. al, 2013). As a reference value, claddings should not have a solar radiation absorption coefficient $(\alpha)$ higher than 0.7 , unless the wall is protected from solar radiation, direct or indirect. If a façade cladding has several colours (Table 1) and the difference of this coefficient between adjacent colours is higher than 0.2, a joint must be created (Freitas 2002). Other sources also report that the colour of the cladding can be evaluated through the luminosity coefficient (measured in HBW), which measures the reflection of incoming light (radiation) and whose minimum values should be between $20 \%$ and $30 \%$. As a reference white has a value of $100 \%$ and black of $0 \%$ (EAE 2011).

\section{[INSERT TABLE 1]}

Maintenance work (Silva and Falorca 2009), as a guarantee of the system's durability, is directly linked to its potential anomalies and their repair, in particular the development of stains and cracking. Previous research has focused on anomalies in ETICS (Daniotti and Paolini 2005) (Amaro et al. 2013), and inspection and diagnosis methods have been proposed, together with repair techniques (Amaro et al. 2014).

\section{ARCHITECTURAL INTEGRATION OF ETICS IN REHABILITATION}

Having explained some of the principles guiding the use of ETICS in the rehabilitation of façades, some standard solutions to integrate the system in window/door frames and 
the upper/lower limits of façades are now proposed. Given the geometric characteristics of these elements, especially the window/door frames, the details presented can also be used to integrate ETICS with any other salient elements the façades might have. These solutions complement other detailing proposals made by the authors in another paper (Fernandes and de Brito 2012).

The first solution (Figure 2) concerns a window-frame with a stone casing. The main difficulty in integrating the system with this type of frame is the stone casing, which risks losing its aesthetic prominence and no longer protrudes from the façade because of the thickness of the ETICS boards, in addition to losing its function as a sill.

\section{[INSERT FIGURE 2]}

The concept behind solution S1 (Figure 2) is to make the thermal insulation next to the stone casing thinner, thereby allowing it to continue to protrude from the façade and maintain its architecture.

Solution S2 (Figure 3) differs from S1 in that the original stone casing was removed from the wall, creating grooves in the masonry to prevent the reduction of the size of the window frame, and refitting the casing after installing extruded polystyrene (XPS) thermal insulation boards (XPS, because it is denser than EPS and more resistant) underneath and behind the casing.

[INSERT FIGURE 3, 4 AND 5]

Solutions S3 and S4 (Figures 4 and 5) apply to window frames with a rendered casing, stone sill, external shutter box visible from the outside and double-panel ceramic hollow brick walls. The difficulty in this case lies with the edge finishing of the system against the shutter box and the sill, given their shape. The proposal in Figure 4 has a bevelled 
edge to reduce the thickness of the boards around the edges of the window frame, and there are metal profiles under the sill to provide protection to the boards from above; furthermore, it keeps the shutter box visible. The proposal in Figure 5 involves covering the shutter box and the sill end with the thermal insulation, in both cases using metal profiles to protect the vulnerable tips of the boards.

The lower end of the façade is another element where it is difficult to integrate the system because, as it is an area likely to suffer impacts the durability of ETICS will certainly be jeopardised. This means placing the lower protecting profile $15 \mathrm{~cm}$ above the ground, as seen in solution S6 (Figure 6, right) and fitting denser, less sensitive to rising damp and more durable extruded polystyrene boards in the lower area, in order to improve the system's durability. Meanwhile, another solution (S5) is suggested for façades less susceptible to impacts whereby the edge is only $3 \mathrm{~cm}$ above the ground/floor, thus disguising the increased thickness due to the system (Figure 6, left).

\section{[INSERT FIGURE 6]}

In order to maintain the rehabilitated façade's image and thus integrate it with its surroundings, it is sometimes necessary to clad the thermal insulation system with other types of material. The most common claddings on the buildings analysed are natural stone, ceramic tiles, traditional render and paint. Of these, traditional render and paint are most easily reproduced by the finishing coat of the system, which already has the right texture and pigmentation.

According to the technicians who fit this system, natural stone cladding can be installed over ETICS by gluing (with traditional or modified mortars) and additional mechanical fasteners. Mechanical fastening is also recommended to supplement the direct adhesion of the ETICS boards to substrates with original claddings of low adhesion strength to 
gluing mortars, walls with ceramic tiling as overall cladding and on façades over $10 \mathrm{~m}$ tall and directly exposed to wind.

As a rule, direct adhesion by gluing is not really appropriate for external claddings because they are liable to suffer anomalies, e.g. detachment, ungluing and moisture stains (Amaro et al. 2014) (Veiga 2004).

Ceramic cladding may be installed over ETICS up to a given height. For this, the thermal insulation boards must be of higher density (XPS) and direct adhesion by gluing must be supplemented with mechanical fastening, preferably using at least 6 fasteners per board, depending on the technicians installing the system. The boards' dowels must be placed in the first layer of base coat mortar while it is fresh once the reinforcement has been put in place. Ceramic cladding can be glued to the base coat or to the primer coat (if any) at least seven days after this has been applied. Furthermore, the general procedures for gluing ceramic cladding on façades should be observed when they are applied over ETICS.

Whenever another cladding is used together with the ceramic one the interface between the different claddings must be designed to guarantee the watertightness of the whole system and to take into account the differences in terms of deformation behaviour of the materials.

When ceramic (Figure 7, left) or stone (Figure 7, right) cladding is used on the façade's lower area one solution is to clad the ETICS with elements that resemble the original ones as closely as possible. In addition to gluing, an adequate mechanical fastening must be considered that does not involve removing the original cladding, as long as the substrate withstands the loading.

\section{[INSERT FIGURE 7]}

For the upper part of the façades the solutions suggested are not significantly different from the existing ones. It is important to guarantee the protection of the upper part of 
the system using capping and profiles fitted with a drip at its end (Figure 8, right). Any rainwater drains have to be removed and reinstalled after the system has been fitted (Figure 8, left), taking into account the increased thickness of the façades when they are refastened to the substrate.

[INSERT FIGURE 8]

\section{DISCUSSION OF SOLUTIONS}

The standard solutions proposed were analysed and evaluated according to their integration in the façade, applicability, associated costs, and durability, as seen in Table 2. The qualitative critical evaluation of the costs of the solutions presented here was based on the data provided by people who install these systems. It was thus considered that the most cost-effective solutions are those whose application does not interfere with the façade elements, and therefore none of them needs to be removed or replaced.

[INSERT TABLE 2]

It was also found that the solutions that consist of covering the existing claddings with expanded polystyrene followed by a thin coat used in ETICS cost more than the previous one, especially when the façade's geometry is not regular and will therefore need the in situ preparation of expanded polystyrene moulds.

The cost comparison was based on solutions where the thermal insulation was the same thickness, since the overall cost of the solution directly depends on that parameter.

The durability of the solutions designed is related to their geometry, including the finished edges and the final cladding of the elements. Furthermore, it depends on whether they are likely to suffer impacts and exposure to rainwater, as protruding elements and window sills are. 
The medium durability solutions are those that involve installing new ceramic or stone cladding over the existing one, since this new cladding may develop anomalies, e.g. detachment, even though it protects the system against impacts and rainwater action.

The high durability solutions are those that are protected from the action of rainwater, from both above and below, by aluminium board profiles with drip moulds projecting away from the façade plane, besides being protected from shocks and impacts.

When it comes to the feasibility of the solutions it is concluded that generally they are not difficult to execute and that the medium or high difficulty ones are also more costly. These are the solutions that involve covering the cladding or façade elements and those that require the reinstallation of elements such as the stone window casing. This difficulty is due to: i) having to cut and mould the thermal insulation boards to fit them to the geometry of the façade; ii) subsequently applying the reinforced base coat to fit the contour and cladding of the façade, and iii) adapting the elements removed and reinstalled to accommodate the surrounding area that has been changed because of the grooves made to release the elements.

As for the architectural integration of the solutions proposed, the ones that are more difficult to install and costlier are generally better integrated, particularly in window/door frames.

The other solutions generally offer reasonable integration because they do not interfere with the façade's elements, are less expensive, easier to apply but also less durable.

\section{CONCLUSIONS}

Having proposed solutions capable of thermally rehabilitating façades, it is concluded that to adequately integrate the solution in the façade it is necessary in most cases to interfere with the existing elements to cope with the different thickness of the insulation, 
and to accept higher costs to obtain better quality integration.

Given their characteristics, the window/door frames are the most complex elements in terms of integrating the external thermal retrofitting, since they function as frontiers against which ETICS need to be fitted. The other construction elements also pose some problems, though the integration solutions are similar to those for frames.

For some buildings the design of the façade element may be significantly changed if the integration solutions are not analysed individually.

In real situations it is possible to integrate ETICS by analysing the solution targeted in order to improve the thermal performance of the outer envelope. However, one needs to ascertain how much the façade's image can be altered, which can only be done at the design and detailing stage, and see how to minimise such change or else opt for another thermal retrofitting solution.

The proposals are only a starting point for the development of other solutions and adaptations to specific cases. It is therefore recommended 3-D models of the system are made and tests performed at the detailing stage. It must then be taken into account that the less costly, easier-to-apply and medium durability solutions do not fully correct thermal bridges because they do not completely cover the existing façade elements. Conversely, the best solution in terms of architectural integration (S2) may not necessarily be the best one from a thermal point of view.

The designer has the duty of integrating and designing the finishing details of ETICS on the façade to be rehabilitated, looking for solutions or alternatives with the expert installers of the system to obtain well-executed solutions. They must also predict the architectural integration of the solutions and fit them to their durability, always keeping their cost and feasibility in mind. 


\section{ACKNOWLEDGEMENTS}

The authors gratefully acknowledge the support of the ICIST Re-search Institute, IST, Technical University of Lisbon and the FCT (Foundation for Science and Technology).

\section{REFERENCES}

Amaro B, Saraiva D, de Brito J, Flores-Colen I. 2013. Inspection and diagnosis system of ETICS in walls, Construction and Building Materials, 47, 1257-1267

Amaro B, Saraiva D, de Brito J, Flores-Colen I. 2014. Statistical survey of the pathology, diagnosis and rehabilitation of ETICS in walls, Journal of Civil Engineering and Management, 20(4), 511-526.

Barreira E, Freitas V. 2005. Importance of thermography in the study of ETICS finishing coating degradation due to algae and mildew growth, $10^{\text {th }}$ International Conference on Durability of Building Materials and Components, Lyon, France.

Barreira E, Freitas V. 2007. Evaluation of building materials using infrared thermography, Construction and Building Materials 2007, 21 (1), 218-224.

Barreira E, Freitas V. 2008. Defacement of ETICS cladding due to hygrothermal behaviour, $11^{\text {th }}$ International Conference on Durability of Building Materials and Components, Istanbul, Turkey.

Collina A. 2007. Comfort and energy saving: the external thermal insulation composite system (ETICS), 2 $2^{\text {nd }}$ National Congress of Construction Mortars, APFAC, Lisbon, Portugal.

Collina A, Lignola G. 2010. The external thermal insulation composite system (ETICS). More than comfort and energy saving, $3^{\text {rd }}$ National Congress of Construction Mortars, APFAC, Lisbon, Portugal.

Daniotti B, Cecconi FR, Paolini R. 2011. Effects of ageing and moisture on dynamic 
thermal performance of ETICS cladding, $12^{\text {th }}$ International Conference on Durability of Building Materials and Components, Porto, Portugal.

Daniotti B., Paolini R. 2005. Durability design of external thermal insulation composite systems with rendering, $10^{\text {th }}$ International Conference On Durability of Building Materials and Components, Lyon, France.

Daniotti, B, Paolini, R. (2008) Evolution of Degradation and Decay in Performance of ETICS. 11 DBMC International Conference on Durability of Building Materials and Components, Turkey.

Dylewski R., Adamczyk J. 2011. Economic and environmental benefits of thermal insulation of building external walls, Building and Environment, 46 (12), 2615-2623.

EAE 2011. European guideline for the application of ETICS, European association for external thermal insulation composite systems, Germany.

EIMA 2008. Exterior wall cladding performance study, EIFS Industry Members Association, Georgia, USA.

EOTA 2000. ETAG 004, Guideline for European technical approval of external thermal insulation composite systems with renderings, European Organisation for Technical Approvals, Brussels, Belgium.

Fernandes C, de Brito J. 2012a. Thermal retrofitting of façades - Architectural integration of ETICS, Journal of Architectural and Planning Research, (submitted for publication).

Freitas V. 2002. Thin reinforced mortar over expanded polystyrene - ETICS (System "HOTSKIN") (in Portuguese), External thermal insulation of façades, MAXIT Technologies of Construction and Renovation Ltd., Porto, Portugal.

HHA 1999. Sustainable Homes: Embodied energy in residential property development, Hastoe Housing Association, England. 
Künzel H, Künzel HM, Sedlbauer K. 2006. Long-term performance of external thermal insulation systems (ETICS), ACTA Architectura, 5 (1), 11-24.

Künzel HM, Zirkelbach D. 2008. Influence of rain water leakage on the hygrothermal performance of exterior insulation systems, $8^{\text {th }}$ Nordic Building Physics Symposium, Copenhagen, Denmark, 253-260.

Lucas S, Ferreira VM. 2010. Selecting insulating building materials trough an assessment tool, SB10 Portugal: Sustainable Building Affordable to All, Vilamoura, Portugal.

Malanho S, Veiga R. 2011. Performance of external thermal insulation composite Systems (ETICS) with finishing ceramic tiles", 12 ${ }^{\text {th }}$ International Conference on Durability of Building Materials and Components, Porto, Portugal.

Mills F, Lawrence T, Rakheja A, Darwich A. 2012. Green building practices around the world, ASHRAE Journal, 1, pp. 48-55.

Norvaisiene, R., Griciuté, G., Bliudzius, R. and Ramanauskas, J. (2013) The changes of moisture absorption properties during the service life of external thermal insulation composite system. Materials Science, 19(1), 103-107.

Paiva J. 2003. Energy rehabilitation measures in buildings (in Portuguese), $2^{\text {nd }}$ Edition, National Laboratory of Civil Engineering, Lisbon, Portugal.

Pereira V, Sequeira P, Barreto J, Silva L. 2007. ETICS as an excellence technique for the rehabilitation of buildings from the second half of the $20^{\text {th }}$ century (in Portuguese), $2^{\text {nd }}$ National Congress of Construction Mortars, APFAC, Lisbon, Portugal.

Silva R, Falorca J. 2007. Advances in ETICS behaviour analysis and consequences for planning maintenance, CIB World Building Congress 'Construction for Development', Cape Town, South Africa.

Silva R, Falorca J. 2009. A model plan for buildings maintenance with application in 
the performance analysis of a composite facade cover, Construction and Building Materials, 23 (10), pp. 3248-3257

Vaz-Sá A, Rangel B, Sousa H, Abrantes V. 2007. Why insulate? The arguments for sustainability, CIB World Building Congress 'Construction for Development', Cape Town, South Africa.

Veiga R. 2004. External wall coatings. Learning course (in Portuguese), $2^{\text {nd }}$ National Congress on Construction, Porto, Portugal. 
Table 1 - Solar radiation absorption coefficients of the finishing coat of ETICS for various colours (EIMA 2008)

\begin{tabular}{ll}
\hline Surface colour & Coefficient $\boldsymbol{\alpha}$ \\
\hline White & 0.2 to 0.3 \\
\hline Yellow, cream, orange, light red & 0.3 to 0.5 \\
\hline Dark red, light green, light blue & 0.5 to 0.7 \\
\hline Brown, dark blue, dark green & 0.7 to 0.9 \\
\hline Dark brown, black & 0.9 to 1.0 \\
\hline $\boldsymbol{\alpha}:$ Solar radiation absorption coefficient
\end{tabular}


Table 2 - Critical comparison of the standard solutions proposed

\begin{tabular}{ccccc}
\hline & Cost & Durability & Feasibility & Architectural integration \\
\hline S1 & Low & Medium & Easy & Medium \\
\hline S2 & High & High & Difficult & Good \\
\hline S3 & Low & Medium & Easy & Medium \\
\hline S4 & Medium & Low & Medium & Reasonable \\
\hline S5 & Low & Low & Easy & Reasonable \\
\hline S6 & Low & Low & Easy & Medium \\
\hline S7 and S8 & Medium & Low & Easy & Reasonable \\
\hline S9 and S10 & Low & Medium & Easy & Reasonable \\
\hline
\end{tabular}




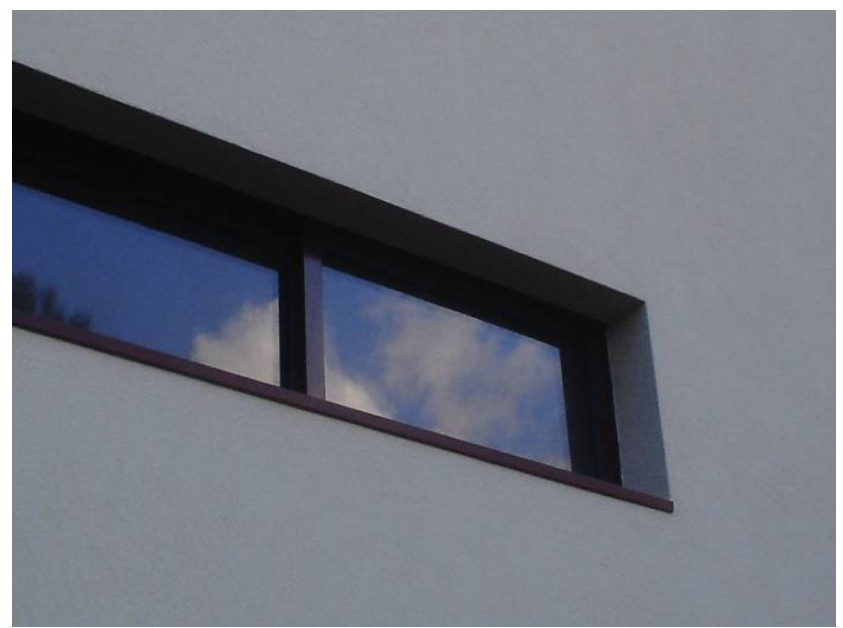

Figure 1 - Metal sill at the bottom of the window frame 

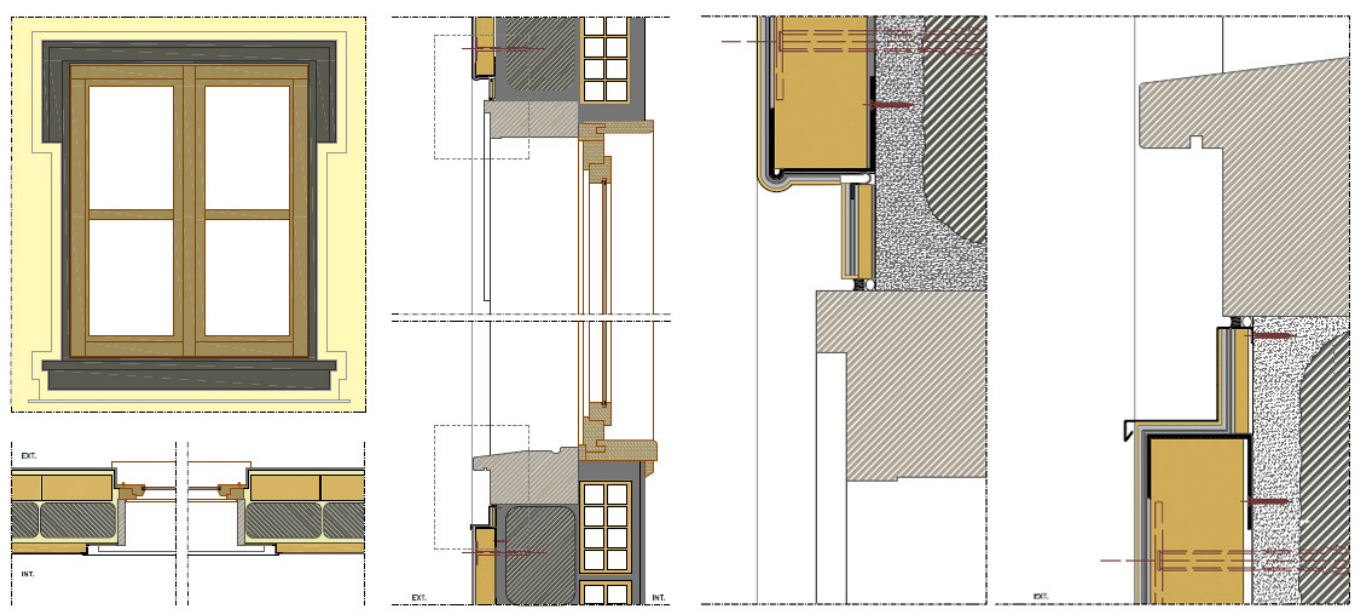

Figure 2 - Solution S1 using ETICS fitted against a protruding window casing (no scale) 


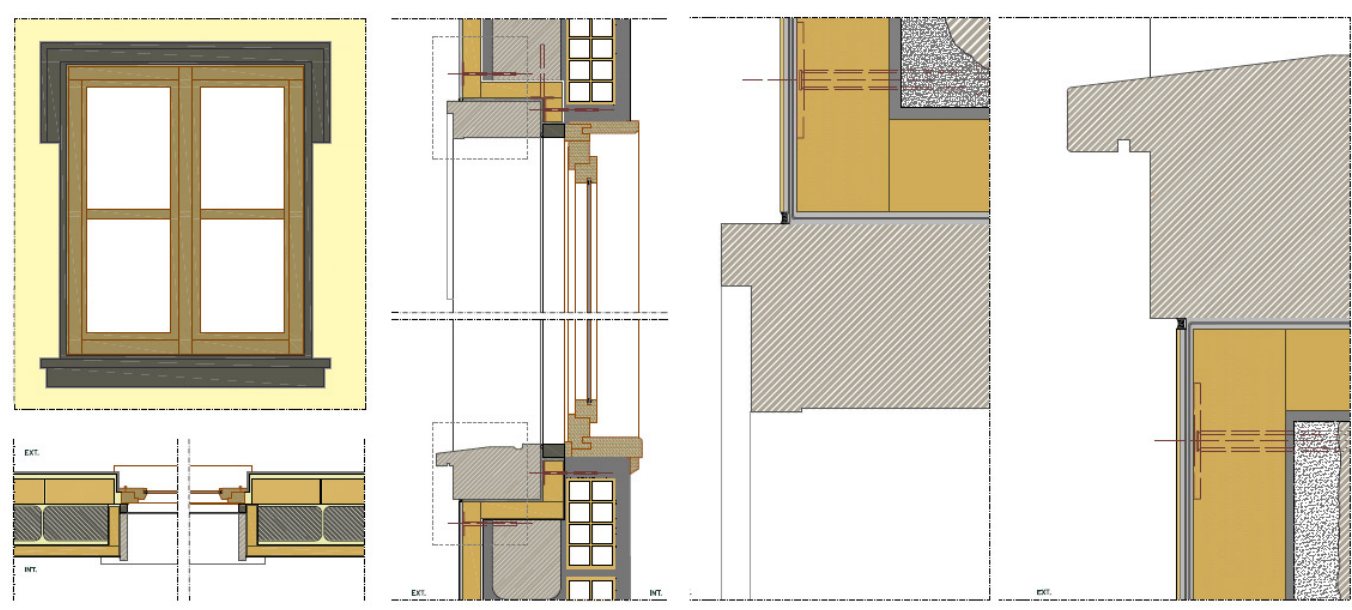

Figure 3 - Solution S2 with reinstallation of the window casing (no scale) 

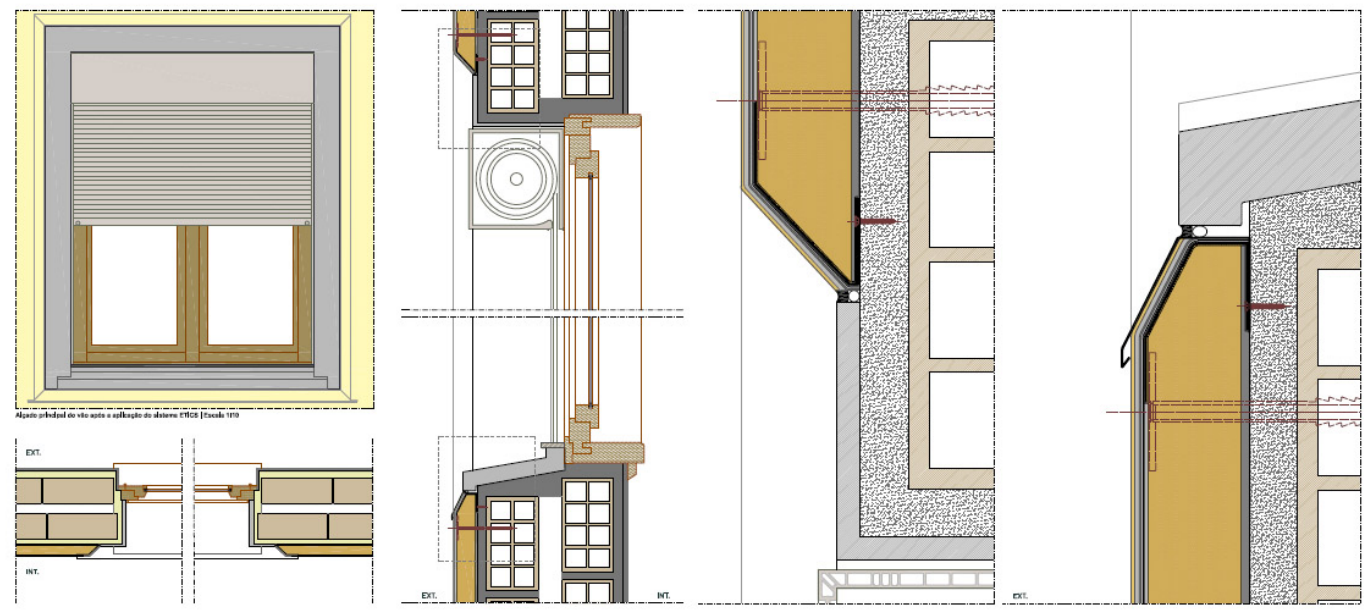

Figure 4 - Solution S3 with finished edges against a protruding window casing with bevelled thermal insulation plates (no scale) 

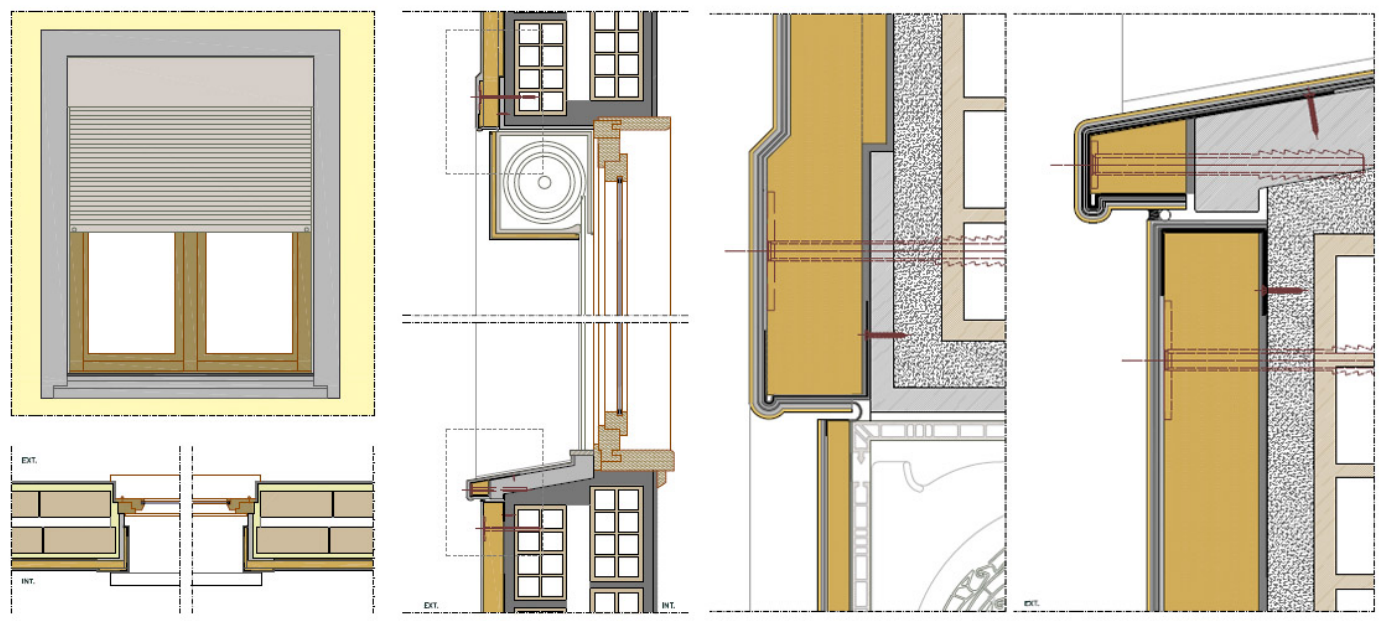

Figure 5 - Solution S4 with finished edges against a window casing made over the original one with extension of the sill in expanded polystyrene (no scale) 


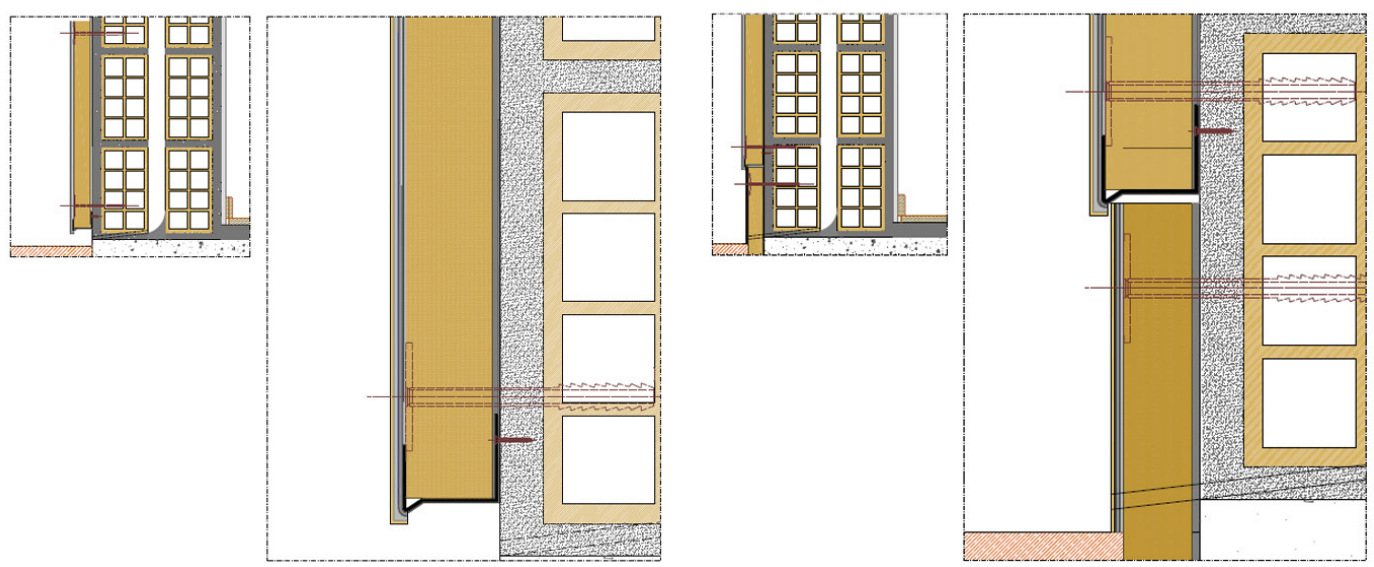

Figure 6 - Solutions S5 and S6 to integrate the lower end of the façade with a profile $3 \mathrm{~cm}$ above the floor (left) and $15 \mathrm{~cm}$ above the floor (right) (no scale) 


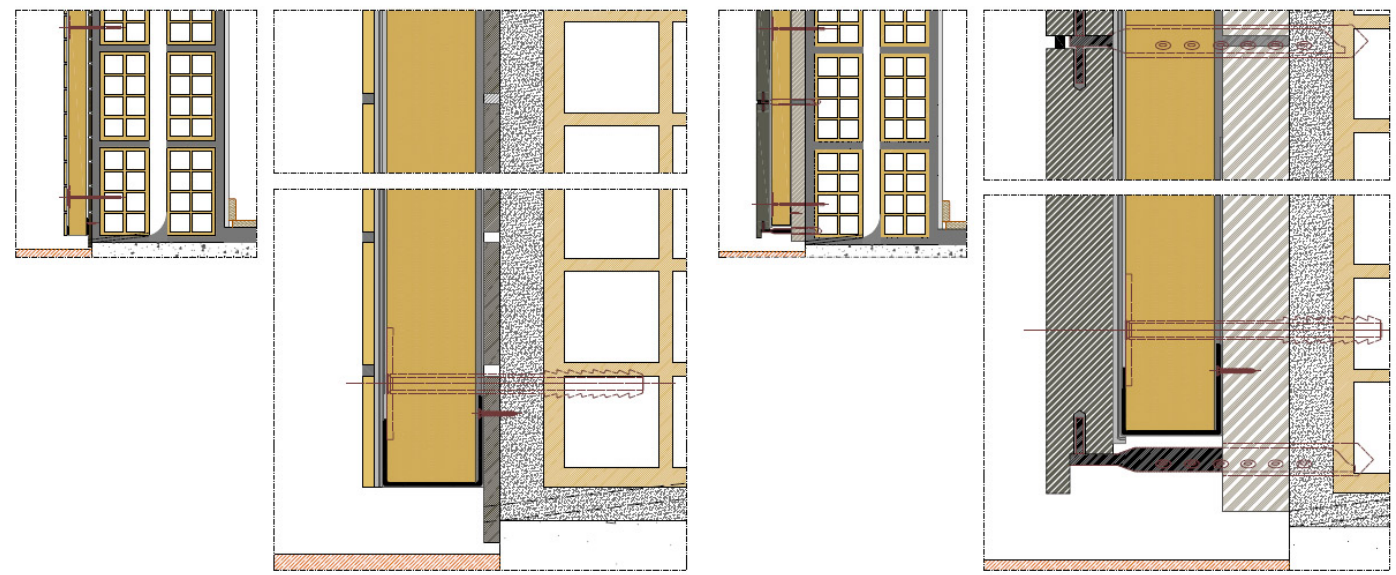

Figure 7 - Solutions S7 and S8 to integrate the lower end of the façade with ceramic cladding (left) and natural stone cladding (right) (no scale) 

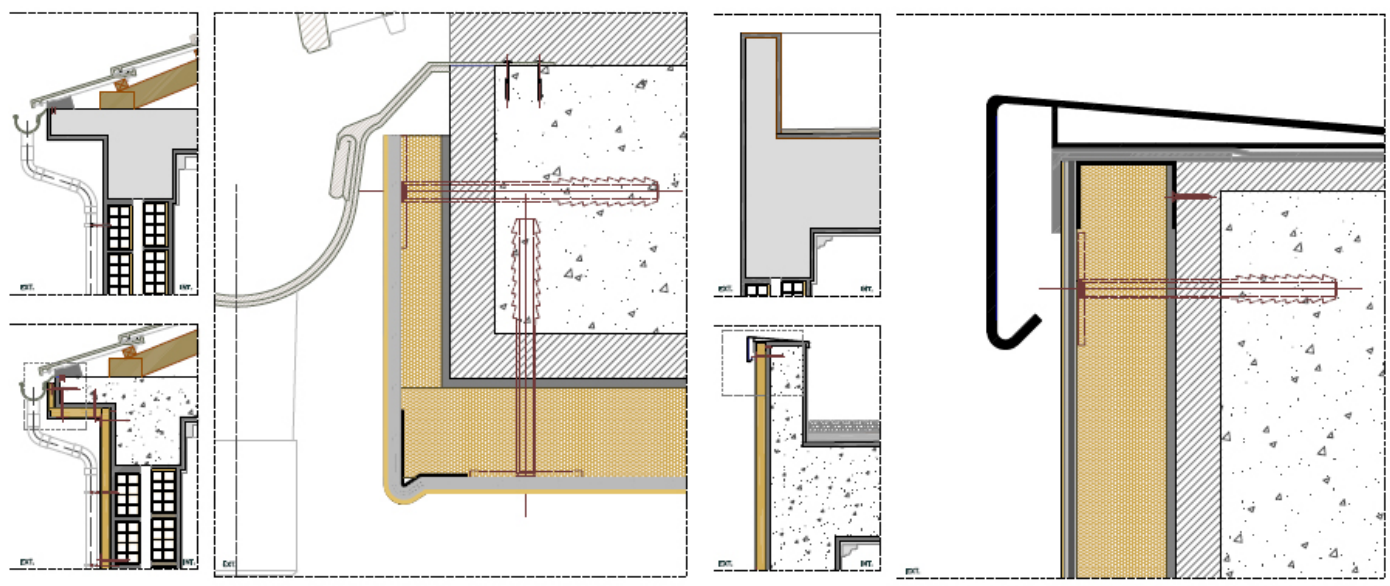

Figure 8 - Solutions S9 and S10 to integrate the upper end of the façade over traditional sloped roof eave (left) and over rendered parapet of flat roof (right) (no scale) 